\title{
ScIDoC
}

\author{
International Journal of Ophthalmology \& Eye Science (IJOES) \\ ISSN: 2332-290X
}

\section{Epidemiological and Clinical Profile Of Fever Related Retinitis: A Hospital Based Study}

Soumya Harapanahalli Venkatesh ${ }^{1 *}$, Anita Timmanalli Girish ${ }^{1}$, Mangala Maritimmanalli Naranappa ${ }^{2}$, Prabhakar Srinivasapuram Krishnachari ${ }^{3}$, Bindu Malini ${ }^{4}$, Darshan ${ }^{4}$, Premnath Raman ${ }^{5}$, Maheshwari Shivaswamy ${ }^{6}$, Dr Veena C N

${ }^{1}$ Associate Professor, Ophthalmology, JSSAHER, Mysuru, Karnataka, 570004, India.

${ }^{2}$ Consultant, Ophthalmology, JSSAHER, Mysuru, Karnataka, 570004, India.

${ }^{3}$ Professor and Head, Ophthalmology, JSSAHER, Mysuru, Karnataka, 570004, India.

${ }^{4}$ Assistant Professor, Ophthalmology, JSSAHER, Mysuru, Karnataka, 570004, India.

${ }^{5}$ Professor, Ophthalmology, JSSAHER, Mysuru, Karnataka, 570004, India.

${ }^{6}$ Post Graduate, Ophthalmology, JSSAHER, Mysuru, Karnataka, 570004, India.

\section{Abstract}

Purpose: Retinal manifestations after a febrile illness irrespective of the etiology can be a common yet enigmatic presentation to an ophthalmologist. Detailed examination and timely diagnosis would go a long way in preventing visual loss in such cases. This study was undertaken to unravel the mystery of fever related retinitis, its clinical course and management.

Methods: This was a retrospective study conducted from June 2016-17 in which medical records of 21 patients were collected. All patients had undergone detailed ocular examination that included best-corrected visual acuity (BCVA), color vision, pupillary reactions, anterior and posterior segment evaluation and fundus photography. Fundus Fluorescein Angiography (FFA) and Optical Coherence Tomography (OCT) were done on a need basis. Routine investigations and specific serology for viral diseases were done as and when required.

Results: 37 eyes of 21 patients of whom 16 bilateral and 5 unilateral were studied. Most patients presented within 1 month following febrileillness. 4 patients were Mantoux positive $(>20 \mathrm{~mm}) .1$ patient each had Dengue IgG and Chickungunya IgG positive respectively. Fundus examination revealed features of retinitis with single or multiple patches with exudation at macula; and all patients were given tapering dose of systemic steroids as per clinical response; specific treatment given as per the cause.Patients with unilateraldiseaseshowedan improvement invision to an average of $6 / 9$ and bilateral cases to an average of $6 / 24$ in the better eye.

Conclusion:The clinical presentation and a favorable response to steroids, were strikingly similar in all cases despite the varied etiology. This study shows that inflammation probably may play a major role in the occurrence of retinal manifestations following an attack of febrile illness.

Keywords: Fever Related Retinitis; Retinitis; Systemic Steroids; Neuro Retinitis, Macular Edema; Chikungunya; Dengue Fever.

\section{Introduction}

Uveitis and retinal inflammation can be due to infective or noninfective etiology. Among them infection as a cause of uveitis is caused by bacteria, virus or parasites. The differential diagnosis includes herpes virus family, syphilis, toxoplasmosis, tuberculosis, Bartonellosis, Lyme disease [1]. In a tropical country like India, there are also many emergent and resurgent infections which are transmitted by the bite of the arthropods to humans. The various arthropod vector borne diseases are mainly viral and include West Nile virus (WNV) infection, Rift Valley fever (RVF), Dengue fever (DF), Chikungunya, and rickettsioses. Systemic involvement varies from a febrile illness to severe lethal disease [2].

The most common ocular manifestation in patients with history of fever include uveitis and neuro retinitis. The others are conjunctival congestion, dacryoadenitis, episcleritis and panophthal-

\section{*Corresponding Author:}

Soumya Harapanahalli Venkatesh,

Associate Professor, Ophthalmology, JSSAHER, Mysuru, Karnataka, 570004, India.

Tel: 09448116151

E-mail: soumyahv@jissuni.edi.in

Received: April 24, 202

Accepted: June 22, 2021

Published: June 23, 2021

Citation: Soumya Harapanahalli Venkatesh, Anita Timmanalli Girish, Mangala Maritimmanalli Naranappa, Prabhakar Srinivasapuram Krishnachari, Bindu Malini, Darshan, et al., Epidemiological and Clinical Profile Of Fever Related Retinitis: A Hospital Based Study. Int J Ophthalmol Eye Res. 2021;9(3):462-466.

doi: http://dx.doi.org/10.19070/2332-290X-2100093

Copyright: Soumya Harapanahalli Venkatesh ${ }^{\circ} 2021$. This is an open-access article distributed under the terms of the Creative Commons Attribution License, which permits unrestricted use, distribution and reproduction in any medium, provided the original author and source are credited. 
mitis. These manifestations occur either due to a direct invasion of the organism or due to an immunological response to the organism [3]. Immunocompetent patients usually present within 2 to 4 weeks after fever with sudden onset painless diminution of vision3, afferent pupillary defect and uveitis [4].

Posterior segment involvement maybe in the form of varying grades of vitritis, focaland multifocal patches of retinitis, optic nerve involvement, serous detachment at the macula, macular edema and localized involvement of retinal vessel [3]. Neuroretinitis is inflammation of the optic nerve and retina [5] characterized by optic disc edema, along with peripapillary and stellate macular subretinal and intraretinal exudates with some amount of associated vitreous inflammation [4].

Currently there is no specific proven treatment for arboviral diseases transmitted by arthropods, and hence therapy is mostly supportive [2]. Patients take several months for visual recovery and recurrences though rare are a possibility [4].

The pattern of uveitis with typical fundus findings, systemic manifestations, and serological tests forspecific antibodies help in arriving at a diagnosis and thus in the management [1].

On literature review not many studies are available describing various manifestations of viral retinitis. The purpose of this study is to analyze the clinical presentation of fever related retinitis due to various etiologies, its course and management.

\section{Materials and Methods}

This was a retrospective study of 21 consecutive out patients who presented to the Department of Ophthalmology of JSS Medical College and Hospital, Mysuru during the period of June 2016 June 2017 and patient details were extracted from the Medical Records department.

Inclusion criteria in this study were unilateral and bilateral cases of fever related retinitis.

Patients with media opacity precluding fundus examination, preexisting macular or optic nerve pathology or any preexisting retinopathy causing diminution of vision were excluded.

All patients underwent a detailed ocular examination which included- visual acuity assessment by Snellens chart, best-corrected visual acuity (BCVA), colour vision, pupillary reactions, anterior and posterior segment evaluation, intraocular pressure and fundus photography. Fundus Fluroscein Angiography (FFA) and Optical Coherence Tomography (OCT) (Zeiss OCT 200) were done as per need. Patients were subjected to regular follow up ranging 2 to 5 months from the onset of symptoms as per the response to treatment.

Basic laboratory investigations were performed at the 1 stvisit. These included complete haemogram, erythrocyte sedimentation rate, venereal disease research laboratory tests (VDRL), human immunodeficiency virus (HIV) Enzyme-Linked Immunosorbent Assay (ELISA), Mantoux test and chest X-ray.

Other investigations were carried out on subsequent visits based on disease progression which included Dengue $\mathrm{IgG} / \mathrm{IgM}$, Toxoplasma IgG/IgM, Chikungunya IgG/IgM, MRI Brain and B scan.

\section{Results and Discussion}

Thirty-seven eyes of 21 patients (16 males and 5 females) were included in this study. The age of the patients ranged from 22 to 60 years with a mean of 32.2 among the females and 37.25 years among the males. Most patients had presented within 7 days of diminution of vision, with two patients presenting after 2 weeks and one presenting after 3 months as he was treated initially elsewhere.

All patients had a history of fever lasting for at least 4 to 5 days with or without joint pains, except one whose fever lasted for about 20 days. The interval between the episode of fever and ocular symptoms ranged from 15 days to 90 days with an average of 25.8days. 16 patients had bilateral disease with unequal presentation and vision in the more affected eye ranged from perception of light negative to $6 \backslash 36$ and lesser-involved eye from counting finger $1 \mathrm{~m}$ to $6 \backslash 6$. Descriptions of the patient characteristics are summarized in Table 1.

The various characteristics of patients who presented unilaterally and bilaterally are depicted in Table 2 .

Anterior segment examination revealed normal pupillary reactions in 23 and afferent pupillary defect in 12 eyes. Two pupils were $6 \mathrm{~mm}$ and non-reacting to light.

Posterior segment examination revealed disc and retinal edema, retinal hemorrhages, retinal infiltrates and macular edema and exudation in the form of macular star. One of them developed serous retinal detachment and another had associated choroiditis. Along with retinitis, there was vitreous haze and cells and 6 eyes had spill over anterior uveitis as well. Fundus photos of unilateral case at diagnosis and follow up is shown. (Figure 1).

Basic laboratory investigations were normal in majority.

Four patients tested highly positive for Mantoux $(>20 \mathrm{~mm}$ in diameter) and one of these also had high Angiotensin Converting Enzyme (ACE) Levels; two showed elevated ESR > 35mm; one patient each had Dengue IgG and Chikungunya IgG positive respectively. MRI Brain along with Optic nerve cuts was done for a patient with 20days of fever, which showed lesions in the frontal lobes and corona radiata; this patient eventually developed post neuritic optic atrophy. All other patients were negative for the common pathogens examined.

OCT done in most of the patients at the time of presentation showed altered foveal contour, increased hyper reflectivity with back scattering and thickening of the inner retinal layers, RPE layer derangement and sub foveal serous detachment. By the end of treatment, there was resolution of edema and serous detachment with regaining of foveal contour and thinning indicative of atrophy. (Figure 2)

All patients were started on steroids $1 \mathrm{mg} / \mathrm{kg}$ body weight and tapered as per clinical response. 2 patients received IV Methylprednisolone $1 \mathrm{~g}$ for 3 days, 3 of them received posterior sub tenon 
Table 1. Table showing the clinical characteristics of patients with retinitis.

\begin{tabular}{|c|c|c|c|c|c|c|c|c|c|c|}
\hline \multirow[t]{2}{*}{ S1 no } & \multirow[t]{2}{*}{$\begin{array}{c}\text { Age/ } \\
\text { sex }\end{array}$} & \multirow[t]{2}{*}{$\begin{array}{l}\text { Involv- } \\
\text { ed eye }\end{array}$} & \multirow[t]{2}{*}{$\begin{array}{l}\text { Pupillary } \\
\text { reactions }\end{array}$} & \multicolumn{2}{|c|}{$\begin{array}{c}\text { Inflammatory } \\
\text { cells }\end{array}$} & \multirow[t]{2}{*}{$\begin{array}{c}\text { Disc } \\
\text { swelling }\end{array}$} & \multicolumn{3}{|c|}{ Retinal findings } & \multirow[t]{2}{*}{$\begin{array}{c}\text { Macular } \\
\text { star/ edema }\end{array}$} \\
\hline & & & & $\mathrm{AC}$ & $\mathrm{VC}$ & & CWS & HEM & SRD & \\
\hline 1 & $23 / \mathrm{M}$ & $\mathrm{BL}$ & RAPD(LE) & - & $2+$ & + & + & + & - & $+(\mathrm{LE})$ \\
\hline 2 & $60 / \mathrm{M}$ & $\mathrm{BL}$ & RAPD (LE) & - & $1+$ & + & + & + & - & $+(\mathrm{LE})$ \\
\hline 3 & $44 / \mathrm{M}$ & UL (LE) & NORMAL & - & $1+$ & + & + & + & - & + \\
\hline 4 & $23 / \mathrm{F}$ & $\mathrm{BL}$ & NORMAL & $+(\mathrm{RE})$ & - & $+(\mathrm{LE})$ & + & + & - & + \\
\hline 5 & $50 / \mathrm{M}$ & $\mathrm{BL}$ & RAPD (LE) & - & $2+$ & + & + & + & - & + \\
\hline 6 & $24 / \mathrm{M}$ & $\mathrm{BL}$ & RAPD (LE) & $2+$ & - & $+(\mathrm{L}>\mathrm{R})$ & + & + & + & NORMAL \\
\hline 7 & $54 / \mathrm{M}$ & $\mathrm{BL}$ & $\begin{array}{l}\text { ILL SUS- } \\
\text { TAINED }\end{array}$ & - & $1+$ & + & + & + & + & + \\
\hline 8 & $40 / \mathrm{F}$ & $\mathrm{BL}$ & NORMAL & - & $2+$ & + & + & + & - & + \\
\hline 9 & $55 / \mathrm{M}$ & $\mathrm{BL}$ & $\begin{array}{l}\text { ILL SUS- } \\
\text { TAINED }\end{array}$ & $1+$ & $1+$ & $+(\mathrm{LE})$ & + & + & - & + \\
\hline 10 & $35 / \mathrm{M}$ & $\mathrm{BL}$ & RAPD BE & - & - & $+(\mathrm{L}>\mathrm{R})$ & + & + & - & + \\
\hline 11 & $43 / \mathrm{M}$ & $\mathrm{UL}(\mathrm{RE})$ & RAPD LE & - & $2+$ & + & + & + & - & NORMAL \\
\hline 12 & $35 / \mathrm{M}$ & UL (RE) & $\begin{array}{l}\text { ILL SUS- } \\
\text { TAINED }\end{array}$ & - & $2+$ & + & - & + & + & NORMAL \\
\hline 13 & $42 / \mathrm{M}$ & $\mathrm{BL}$ & NORMAL & - & - & + & + & + & - & NORMAL \\
\hline 14 & $26 / \mathrm{M}$ & UL (LE) & RAPD (LE) & - & - & $\begin{array}{l}\text { NOR- } \\
\text { MAL }\end{array}$ & + & + & - & + \\
\hline 15 & $24 / \mathrm{M}$ & $\mathrm{BL}$ & NORMAL & - & $1+$ & + & + & + & + & + \\
\hline 16 & $37 / \mathrm{M}$ & $\mathrm{BL}$ & NR (BE) & - & - & + & - & + & - & NORMAL \\
\hline 17 & $40 / \mathrm{F}$ & $\mathrm{BL}$ & NORMAL & KP'S & $2+$ & $\begin{array}{l}\text { NOR- } \\
\text { MAL }\end{array}$ & + & + & - & $+(\mathrm{RE})$ \\
\hline 18 & $28 / \mathrm{F}$ & $\mathrm{BL}$ & NORMAL & KP'S & - & $\begin{array}{l}\text { NOR- } \\
\text { MAL }\end{array}$ & - & + & - & NORMAL \\
\hline 19 & $22 / \mathrm{M}$ & $\mathrm{BL}$ & NORMAL & - & $2+$ & + & + & + & - & $+(\mathrm{RE})$ \\
\hline 20 & $22 / \mathrm{M}$ & $\mathrm{BL}$ & NORMAL & $\begin{array}{c}2+ \\
(\mathrm{R}>\mathrm{L})\end{array}$ & $\begin{array}{c}2+ \\
(\mathrm{R}>\mathrm{L})\end{array}$ & + & + & + & + & + \\
\hline 21 & $30 / \mathrm{F}$ & UL (RE) & NORMAL & - & $1+$ & + & + & + & - & + \\
\hline
\end{tabular}

M-Male, F-Female, RE-Right Eye, LE-Left eye, UL-Unilateral, BL-Bilateral, RAPD-Relative Afferent Pupillary Defect, AC-Anterior Chamber, VC-Vitreous Cavity, KP-Keratic precipitates,CWS-Cotton wool spots, HEM-Hemorrhages, SRD-SerousRetinal Detachment, NR- Non reactive.

Table 2. Characteristics of unilateral and bilateral ocular inflammation.

\begin{tabular}{|c|c|c|}
\hline & UNILATERAL & BILATERAL \\
\hline AGE & 35.6 years & 36.18 years \\
\hline SEX & 4 Males, 1 Female & 12 Males, 4 Females \\
\hline $\begin{array}{c}\text { DURATION BETWEEN FEVER AND } \\
\text { ONSET OF VISUAL SYMPTOMS }\end{array}$ & 5.4 Weeks & 3.37 Weeks \\
\hline VA AT PRESENTATION & $1 / 60$ & $3 / 60$ \\
\hline PUPILLARY DEFECTS & 4 & 13 \\
\hline
\end{tabular}

injection of steroids. 4 patients were on oral Ecosprin. Specific treatment like Anti tubercular therapy (ATT) and anti toxoplasmic measures were started as per need.

Three patients were given systemic antivirals along with steroids. Two patients with oral Acyclovir and one with oral Famciclovir when the response to steroids was inadequate and developed fresh lesions while on steroid treatment.

There was a good response to steroids as evidenced by decreasing retinal lesions and improvement in vision over 12 months. There was resolution of retinitis, macular edema and serous RD with increase in hard exudates. Patients with unilateral disease showed an improvement in vision to an average of $6 / 9$ and bilateral cases to an average of $6 / 24$.

Irrespective of the aetiology, Post-fever retinal manifestations are usually seen within 2-3 weeks after the onset of fever. Apart from focal or multifocal patches of retinitis, patients present with anterior uveitis, macular edema, and serous detachment at the macula. The retinitis could be unilateral or bilateral [3]. 
Figure 1. Fundus picture of right eye of a patient who presented with history of fever 3 weeks back and diminution of vision 1week later 1A: Areas of diffuse infiltrates close to inferior vascular arcade and macular star. 1B: Reduction of infiltrates and appearance of hard exudates at macula post treatment.

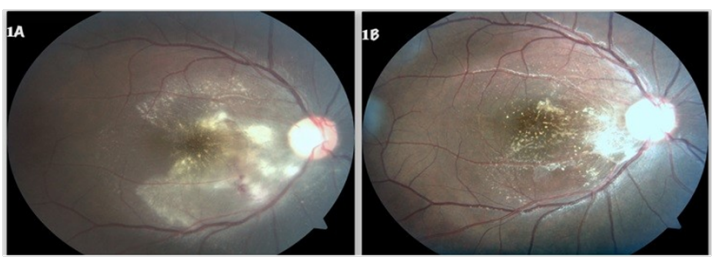

Figure 2. OCT changes of a patient over 6 weeks who presented with right eye diminution of vision since 1 week with history of fever 3 weeks back. 2A: At Presentation: OCT through macula showing serous detachment, inner retinal hyper reflectivity with backscattering over lesion. 2B: 2 weeks after treatment: Decreasing edema with Small pocket of fluid subretinally and inner retinal hyper reflectivity .2C: 6 weeks after treatment: Complete resolution of edema with regaining of foveal contour.
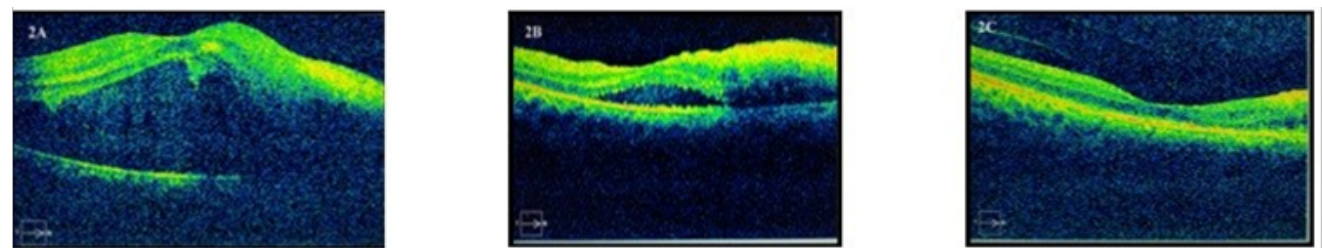

In our study, the interval between episode of fever and ocular symptoms ranged from 15 days to 90 days with an average of 25 . 8days.All our patients showed good response to steroids.

The various infective causes of retinitis are Herpes, Syphilis, Toxoplasmosis, Tuberculosis, Bartonellosis, Lyme disease1 and arthropod vector borne diseases which are mainly viral, include West Nile virus (WNV) infection, Rift Valley fever (RVF), Dengue fever (DF), Chikungunya, and Rickettsioses [2]. A thorough literature search showed this study to be the largest series of fever related retinitis from a single center.

Chikungunya viral infection can cause various ocular manifestations like non-granulomatous/granulomatous anterior uveitis, episcleritis, pan uveitis, optic neuritis, sixth nerve palsy, retro bulbar neuritis, retinitis with vitritis, neuroretinitis, keratitis, central retinal artery occlusion, choroiditis, exudative retinal detachment, and secondary glaucoma [6]. A study conducted by Apoorva Mittal et al suggested that patients suffering from Chikungunya infection can present with acute inflammation of optic nerve who respond well to steroid therapy [7]. One of our patients had Chikungunya IgG positive and presented with diminution of vision after 3 months of fever as he had been treated elsewhere for fever. He had corneal opacity in the RE since 3 years. Apart from retinitis and RAPD, he also had choroiditis and vitritis. $\mathrm{Pa}$ tient's vision improved from $6 / 60$ at initial presentation to $6 / 9$ at 2months follow up after steroid therapy.

Dengue fever caused by the Dengue virus, is a flavivirus transmitted by the bite of the Aedes aegypti mosquito. The posterior segment manifestations include retinal haemorrhages, retinal vascular sheathing, yellow sub retinal dots, RPE mottling, foveolitis, choroidal changes, optic disc edema, optic neuritis, and neuroretinitis. There may be associated involvement of anterior segment and vitreous 2 in the form of cells and haze. The affected patient in our study showed Dengue $\operatorname{IgG}$ positive along with a raised ESR, presented with bilateral disc and retinal edema, cotton wool spots, haemorrhages and edema at macula. After an initial good response to steroids in the LE, the patient's vision improved from counting finger close to face to counting finger- $1 \mathrm{~m}$ by 1 month.
However, there was a drop in vision in the RE as the lesions increased in the RE.

Tuberculous retrobulbar optic neuropathy occurring as a complication of systemic infection is well known entity. Rarely secondary to choroiditis or in isolation there can be neuroretinitis as well and should be considered as an etiologic possibility in patients with systemic signs and symptoms suggestive of Tuberculosis4. In our study four patients had Mantoux positive $>20 \mathrm{~mm}$, however their chest X-Ray was normal. These patients had mild vitritis along with retinal infiltrates, haemorrhages and macular edema. 2 patients had unilateral presentation and 2 patients had bilateral involvement. 1 of these patients who also had an elevated ACE levels had spill over anterior uveitis. All 4 patients were started on conventional Anti Tubercular Therapy (ATT) and steroids. They showed good clinical response to steroids as the vision improved within 2 months. Out of 21 patients, 15 of them had all the investigations normal and were considered to be idiopathic in etiology. They responded well to steroid therapy. The response to treatment of some of these 21 patients was different when compared to the common lot. one of these patients had lesions in the frontal lobe and corona radiata as seen on MRI Brain with optic nerve cuts, who eventually developed post neuritic optic atrophy despite steroid therapy and Neurobion supplementation. One patient had retinochoroidal thickening on $\mathrm{B}$ scan along with subfoveal fluid on OCT, but responded dramatically to steroids within 20 days. 2 other patients either developed fresh retinal lesions within 10days of starting steroids or showed no significant response to even posterior sub tenons injection and were hence started on Oral Acivir $800 \mathrm{mg}$.

Following the additional antiviral therapy, patients showed a decline in lesions and an improvement in vision. Studies have shown that fever related retinitis on OCT had highly reflective and disorganized inner retinal layer with back scattering, underlying serous retinal detachment and serous choroidal detachment $[8,9]$. In our study also, the OCT of most of the patients had hyper reflectivity of the inner retinal layers with serous detachment at the macula, which resolved gradually with steroid treatment to regain the normal foveal contour. 
$76 \%$ of patients in this study showed a bilateral involvement and all patients had a good clinical response to oral steroids. All patients had a similar presentation though there were varied etiologies. The exact mechanism of retinal involvement in post fever retinitis is unknown. Several characteristics such as delay in onset, partial recovery of disc changes, bilateral involvement in a few patients, and good response to corticosteroid therapy indicate a possible immunological cause.

\section{Conclusion}

Fever related retinitis manifested approximately 4 weeks after the onset of fever. Despite the varied etiology, all had focal or multifocal patches of retinitis with varying exudation at the macula. All the patients responded well to corticosteroid therapy in terms of abatement of signs and favorable visual outcome suggesting a possible common underlying pathophysiological pathway. Hence this study emphasizes the early need for diagnosis of post fever retinitis and early intervention to achieve a better visual outcome.

\section{References}

[1]. Khairallah M, Chee SP, Rathinam SR, Attia S, Nadella V. Novel infectious agents causing uveitis. Int Ophthalmol. 2010 Oct; 30(5):465-83. Pubmed PMID: 19711015.
[2]. Khairallah M, Kahloun R, Ben Yahia S, Jelliti B, Messaoud R. New infectious etiologies for posterior uveitis. Ophthalmic Res. 2013; 49(2): 66-72. PMID: 23258387.

[3]. Vishwanath S, Badami K, Sriprakash KS, Sujatha BL, Shashidhar SD, Shilpa YD. Post-fever retinitis: a single center experience from south India. Int Ophthalmol. 2014 Aug;34(4):851-7. PMID: 24362635.

[4]. Stechschulte SU, Kim RY, Cunningham ET Jr. Tuberculous neuroretinitis. J Neuroophthalmol. 1999 Sep; 19(3):201-4. PMID: 10494950

[5]. Gass JD. Diseases of the optic nerve that may simulate macular disease. Trans Sect Ophthalmol Am Acad Ophthalmol Otolaryngol. 1977 Sep-Oct; 83(5): 763-70. PMID: 73251.

[6]. Rose N, Anoop TM, John AP, Jabbar PK, George KC. Acute optic neuritis following infection with chikungunya virus in southern rural India. Int J Infect Dis. 2011 Feb;15(2):e147-50. PMID: 21131222.

[7]. Mittal A, Mittal S, Bharati MJ, Ramakrishnan R, Saravanan S, Sathe PS. Optic neuritis associated with chikungunya virus infection in South India. Arch Ophthalmol. 2007 Oct;125(10):1381-6. PMID: 17923547.

[8]. Relhan N, Pathengay A, Albini T, Priya K, Jalali S, Flynn HW. A case of vasculitis, retinitis and macular neurosensory detachment presenting post typhoid fever. J Ophthalmic Inflamm Infect. 2014 Sep 18;4:23. PMID: 25246983.

[9]. Ilhan A, Yolcu U, Altun S, Erdem U, Gundogan FC. Neuroretinitis secondary to Bartonella henselae in the emergent setting. Am J Emerg Med. 2017 Apr; 35(4):647. PMID: 25586979. 